\title{
LO COMÚN EN LA PRAXIS \\ INTERCULTURAL FILOSÓFICA, ÉTICA Y JURÍDICA
}

\section{THE COMMON IN THE PHILOSOPHICAL, ETHICAL AND LEGAL INTERCULTURAL PRAXIS}

Antonio Salamanca Serrano

Universidad Autónoma, San Luis Potosí, México

antoniosalamanca@icam.es

Recibido: octubre de 2021

Aceptado: noviembre de 2021

Palabras clave: Filosofía intercultural, materialismo cultural marxista, sistema de necesidades/capacidades, lo común.

Keywords: Intercultural Philosophy, marxist cultural materialism, system needs/capabilities, the common.

Resumen: El texto aborda el problema del contenido de lo común en la reflexión y práctica (praxis) de las filosofías, las éticas y los derechos de la liberación. Toma distancia crítica con los acercamientos discursivos de cierta deriva idealista burguesa. Se ofrece las posibilidades del materialismo cultural marxista. En contreto, se presenta el disnamismo estructural del sistema de necesidades/capacidades como constante intercultural o transcultural.

Abstract: The text addresses the problem of the content of the common in the reflection and practice (praxis) of the philosophies, ethics and rights of liberation. It takes a critical distance with the discursive approaches of a certain bourgeois idealist drift. The possibilities of Marxist cultural materialism are offered. The structural dysnamism of the system of needs/capabilities is presented as an intercultural or transcultural constant.

\section{Introducción: más allá de la multiculturalidad e interculturalidad burquesas}

La cultura es el modo de vivir y morir de los pueblos con la naturaleza en su historia. La cultura es el "cultivo" de la vida (la muerte es parte de la vida). El cultivo lo es de una infinitud de acciones, una praxis vital. Este es el hecho mayor cultural. Acontecimiento fundante ineludible cuando reflexionamos sobre la práctica intercultural.

El acercamiento que hacemos a la interculturalidad en este texto es una indagación desde el materialismo cultural de tradición marxista, crítico con la interpretación que 
de la misma hacen los acólitos burgueses del capital. Estos han cercenado la cultura y la interculturalidad mutilándolas al menos con seis grandes machetazos:

- La mutilación ideológico-simbólica del zoológico etnográfico. La reflexión intercultural burguesa suele reducir la cultura a las expresiones de museo que llaman ideológicas o simbólicas (religión, filosofías, ciencias, artes, ocio, estética, gastronomía, etc.). La burguesía procura ocultar de sus elucubraciones sobre la interculturalidad los modos de vida económica en sus empresas, los modos sociales nacionales e internacionales de relaciones económicas que condicionan las sociedades locales y globales. También suelen excluir las relaciones de poder o dominación política sistémica, internacionales y mundiales, que condicionan las locales.

- La mutilación escéptica cognitiva y axiológica de la reflexión intercultural. La producción de reflexiones sobre interculturalidad, particularmente académica, ha sido en gran parte colonizada por el escepticismo cognitivo y moral de la burguesía. Resulta llamativo como artículos y libros sobre interculturalidad que tienen entre sus postulados la decolonialidad, no cuestionan uno de los dogmas fundamentales del colonialismo burgués, su escepticismo cognitivo y ético.

- La mutilación interdisciplinar. Es frecuente encontrar propuestas multiculturales e intercuturales que en su crítica del cientificismo moderno eurocéntrico y burgués acaban rechazando toda ciencia, la epistemología científica y la misma apertura interdisciplinar a las culturas de las otras ciencias que no sean la propia filosofía o antropología etnográfica.
- La mutilación voluntarista de la reflexión intercultural. La desmaterialización burguesa de la cultura y su escepticismo cognitivo y moral dejan a la reflexión intercultural reducida al juego de acuerdos intersubjetivos. Eso sí, como sus ideólogos desean mostrarse muy democráticos y no autoritarios, predican que los acuerdos deben tomarse desde abajo y en simetría, ello con ingenuidad cínica que contribuye a ocultar las asimetrías históricas reales de esas voluntades. No tendrán otra brújula que el resultado del juego de sus voluntades.

- La mutilación del diálogo como mediación central de la práctica intercultural. La reflexión intercultural burguesa suele colocar al diálogo como la mediación central de la práctica y reflexión intercultural. Sin embargo, el lenguaje lo suelen reducir al uso lingüístico de la palabra. Les importa menos que el lenguaje sea mucho más que el uso verbal de la palabra. Voluntaristas escépticos, como son, se fugan de las implicaciones del lenguaje de las caricias, de los afectos, del lenguaje estético, ético, etc. Se fugan de la materialidad del lenguaje. No les interesa ahondar en los estratos del lenguaje, en el hecho de que el lenguaje es una reducción de la signación, y que esta es a su vez una reducción de la expresión (X. Xubiri). Ni reconocen ni les interesa escuchar a otro interlocutor, siempre presente en los diálogos, que participa con el otro sujeto -cuando es el caso excepcional de que el sujeto tiene voz en desiertos monológicos-: la naturaleza, que se comunica con su sistema de necesidades y capacidades para la vida y su reproducción.

- La mutilación burguesa de la reflexión intercultural. La reflexión sobre la práctica cultural, entre otras, se ha diferen- 
ciado entre multicultural e intercultural. La primera, multicultural, suele asociarse a planteamientos ideológicamente conservadores, excluyentes y pesimistas respecto a las posibilidades del diálogo para el enriquecimiento mutuo. La segunda, intercultural, es más cercana ideológicamente con el progresismo, la inclusión y el optimismo respecto a las posibilidades del diálogo para una convivencia en la diversidad. Sin embargo, tanto en las reflexiones multiculturalistas (más) como en las interculturalistas (menos, pero también en algunos casos) nos encontramos en ocasiones con que la agenda la han tomado los burgueses con su idealismo y escepticismo cognitivo y axiológico, la aceptación y legitimación más o menos vergonzante de la hegemonía de las relaciones económicas del mercado capitalista, la doctrina de la tolerancia liberal, la forma de la democracia deliberativa representativa, y un sistema jurídico de derechos humanos, leídos, aplicados e impuestos en clave burguesa. Sesgos al servicio de la extracción y acumulación capitalista de la plusvalía ideológica, cultural, económica y de poder de los pueblos.

Ante estos secuestros por parte de la buguesía, de la más genuina reflexión intercultural, desde el materialismo cultural marxista advertimos la importancia que tiene para la reflexión intercultural reconocer en el diálogo a la materialidad de la naturaleza como interlocutor. La materialidad de la vida como sistema de necesidades/capacidades puede que termine ofreciéndonos un gran regalo: la brújula para caminar floreciendo en la diversidad desde la unidad. Lo común, reclamado en el campo jurídico por autores como D. Sánchez Rubio, deja de ser entonces un mero constructo de voluntades comunes para revelarse, como también el autor defiende, en materialidades comunes, condiciones de posibilidad de la diversidad intercultural. La praxis intercultural no es posible solo con la mera prédica discursiva, dialógica, sobre lo bueno y bonito que podríamos acordar para vivir mejor. Es una praxis desde la diversidad en la satisfacción del sistema de necesidades y el florecimiento del sistema de capacidades que nos une como pueblos y especie. La praxis intercutural, en la tradición del materialismo cultural marxista, sabe que tiene que explicar y hacer frente en la práctica de los monólogos culturales existentes, porque hay intereses cínicos y estratégicos que buscan la muerte cultural de los pueblos, e incluso su eliminación genocida.

Este año se celebra el cincuenta aniversario de la Filosofía de la Liberación. Una fecha, que, con precisión, habría que decir que es el aniversario de una corriente de escritos académicos sobre filosofía de la liberación. Un movimiento iniciado en Argentina en la década de los años setenta del siglo XX. Sin duda este bello movimiento de reflexión ha acompañado a muchos movimientos de liberación populares, haciendo la mejor interpretación praxiológica del contenido de la praxis no idealista. Como muchas de sus reflexiones nos han enseñado, la filosofía de la liberación es una praxis cultural, un modo de vivir y pensar y no solo escritos sobre filosofía de la liberación (fetichismo académico); y el sujeto de la filosofía de la liberación no es un autor o grupos de autores solos, sino los sujetos con sus pueblos en el decurso histórico. La práctica cultural de la filosofía de la liberación ha existido antes de esta reflexión académica particular que toma su denominación como identidad. La Filosofía de la Liberación ha tenido el mérito de acompañar 
una práctica reflexiva filosófica propia de emancipación latinoamericana más allá del colonialismo capitalista eurocéntrico. Muchos han sido sus integrantes. Entre ellos se puede citar sus fundadores a Osvaldo Adelmo Ardiles, Mario Casalla, Horacio Cerruti, Carlos Cullen, Enrique Dussel, Rodolfo Kusch, Arturo Andrés Roig, Juan Carlos Scannone, Julio de Zan, Ignacio Ellacuría, etc. El compromiso de este movimiento por la liberación de la colonialidad le llevó pronto a reclamar una práctica y reflexión intercultural. Autores como Raúl Fornet Betancourt pusieron en marcha el proyecto de Filosofía Intercultural en la perspectiva de la liberación más allá del capitalismo. En 2012, Eugenio Nkogo Ondó, Manuel Zapata Carrascal, María Eugenia Jordán Chelini y Nicolás Contreras fundan el proyecto de filosofía intercultural Afro-Indo-Abiayalense (FAIA), caminando hacia una filosofía intercultural de la liberación. Precisamente, en 2021, FAIA acaba de publicar el texto Introducción a la Filosofía Intercultural de la Liberación. Metodologías de la Investigación para el Diálogo Afro-Indo-Abiayalense.

Estas páginas pretenden humildemente aportar en la construcción desde abajo, desde el diálogo de la reflexión metodológica para la investigación filosófica y científica. Se ofrece una modesta contribución a la praxis (también filosofía) intercultural desde la tradición del materialismo cultural marxista. En el texto reivindicamos la ciencia y la epistemología científica como elementos de la liberación de los pueblos, junto a la filosofía. Si la ciencia y su epistemología necesita ser criticada porque en muchas ocasiones se ha impuesto y se impone como saber aséptico, neutral y con servilismos de dominación de clase, eso no puede significar, a nuestro juicio, que los pueblos renuncien a la ciencia como si esta hubiese sido creación de la burguesía europea moderna; y, peor aún, entregarle la ciencia a los burgueses para que entonces refuercen todavía más su dominación. Como hemos indicado arriba, una de las mutilaciones y autocontradicciones del diálogo intercultural sería excluir del mismo la cultura científica interdisciplinar. Eso, por ejemplo, pareciera desprenderse, si es que no son imprecisiones, de los planteamientos de Alexander Ortiz Ocaña y María Isabel Arias López, en Atersofía y Hacer Decolonial, aunque también es cierto que en el texto apuestan por una ciencia de la vida (Proto e Issa, 2021, pp. 116-166). Por el contrario, elocuentes de un bello diálogo intercultural científico son los ejemplos de E. Nkogo en La reconstrucción del puente de comunicación y de conocimiento Afro-Euro-Abiayalense (Proto e Issa, 2021, pp. 30-57), donde evidencia cómo la ciencia griega bebió y aprendió -y también aportó a- de la ciencia de los pueblos negros egipcios. En este espíritu, lo que que aquí sugerimos provienen de optar por escuchar la voz de la naturaleza, tantas veces silenciada pero siempre presente en las praxis culturales. Una voz que algo nos dice para los tres campos de diálogo intercultural que ahora abordamos: la biología, la ética y el derecho.

\section{La constante transcultural: la vida de los pueblos y la naturaleza}

Los descubrimientos en ciencias como la biología, la antropología y otras parecen apoyar el postulado de que la praxis intercultural es posible por la articulación dialéctica entre la constante transcultural del sistema de necesidades y capacidades del homo sapiens sapiens, con la diver- 
sidad histórica de expresiones culturales en su satisfacción y florecimiento. Existe una deriva, que denominamos idealista, en la filosofía intercultural que parece no tomar en cuenta en su quehacer reflexivo los avances de ciencias como la biología, genética, psicobiología, antrobiología, sociobiología, neurociencia cognitiva, neurociencia afectiva de la cognición, neurociencia social, etc. A esta parte de la filosofía intercultural parece no interesarle el diálogo con tradiciones culturales científicas como la egipcia, de la que bebe Demócrito, entre otros. Demócrito, nacido en Adera (Tracia), costa norte de Grecia (460-457 a.C), aprendió ciencia de las culturas científicas de Babilonia, Caldea, Egipto (donde vivió cinco años), Etiopía, India, Mesopotamia, Persia. A Demócrito se le atribuye la frase "todo cuanto existe es fruto del azar y la necesidad". La deriva, que llamamos 'idealista-discursiva' de esa corriente de filosofía asume hacer filosofía intercultural desconociendo los aportes, por ejemplo, de Jaques Monod, premio Nobel de medicina (1965), en obras como El azar y la necesidad (1970). La articulación entre las invarianzas estructurales y las perturbaciones azarosas en los organismos parecen explicar el diamiso histórico evolutivo de las especies, también la humana. En el campo de la filosofía académica, filósofos como X. Zubiri, ya por aquellos años defendían esa articulación. En su obra Estructura Dinámica de la Realidad (1968), X. Zubiri reclamaba de la filosofía tomar en cuenta los avances de la ciencia, porque no se puede hacer filosofía seria sin la ciencia, ni buena ciencia sin la filosofía. Se puede entender que en el siglo XIX, cuando las ciencias nuevas arriba mencionadas no existían y apenas la genética se iniciaba con Mendel, una parte de la filosofía tomara los derroteros idealistas e histori- cistas, pero hoy ya no. Dicho esto, lo que buena parte de estas ciencias constatan es precisamente el hecho de la dialéctica entre una estructura constante propia de la especie, en relación dinámica con sus expresiones culturales históricas. Esa constante la denominamos el Sistema de Necesidades y Capacidades (SNC). Lo que sigue es una presentación esquemática de ese sistema, resultado de un trabajo de investigación, que si el lector tiene interés en profundizar puede consultar en Las fuerzas esenciales del florecimiento (2021), libro que en este momento se encuentra en fase de publicación.

\section{I El SNC: concepto, características, estructura, dinamismo}

\section{2.l.1 Concepto}

La vida de los pueblos es el dinamismo de un sistema estructurado de necesidades/ capacidades 'materiales'. Los seres vivos están urgidos a tomar energía del medio (necesidades), combustionar o transformar esa energía en función de las urgencias del organismo, y a devolver energía al medio (capacidades). EI SNC propio de la especie homo sapiens sapiens es el que aquí abordamos. Cada especie tiene el suyo y comparte algo de la estructura con el resto de especies.

A partir de los descubrimientos científicos, la estructura fundamental psicobiológica de la vida humana, en sentido amplio, se puede entender como la integración de un sistema:

$1^{\circ}$ De una constante energética, físicoquímica, neurobiológica, psicobiológica etc., estructurada tridimensional- 
mente, en interacción sistémica en cada uno de sus componentes entre sí y de estos con todo el sistema. Consiste en 23 pares de cromosomas compuestos por genes (genotipo);

$2^{\circ}$ En comunicación con la energía del medio, con el entorno o medioambiente, atemperándose al mismo mediante cambios orgánicos a través de la extracción, transformación y donación de energía para crear y mantener la estructura constitutiva propia y de las especies. Estructura con componentes físicos, químicos, biológicos, mecánicos, osmóticos, eléctricos, etc.;

$3^{\circ}$ Para un dinamismo energético histórico autorreplicativo, que determina la diferente duración temporal del individuo y la especie. La permanencia de la estructura material del sistema cromosómico y de memoria (genotipo y consciencia) en la autorreplicación permite la permanencia temporal del individuo y de la especie en la pluralidad histórica de expresiones fenotípicas.

\subsubsection{Características}

El SNC tiene una serie de características que le identifican, en parte compartidas por otras especies:

$\left.1^{\circ}\right)$ El SNC de toda especie viva comparte la estructura de la acción vital: a) la función aprehensiva (cognitiva en los animales, jsi no también de las plantas!); b) la función comunicativa; c) la función ejecutiva.

$2^{\circ}$ ) El SNC tiene un modo propio en cada especie de desplegar su estructura (especificidad). En la especie humana, la energía del sistema se expresa en modo físico/químico, biológico, psico- lógico, sociológico, histórico, filosófico, moral, político, etc.

$\left.3^{\circ}\right)$ El SNC del homo sapiens sapiens es una constante transhistórica de la especie.

$\left.4^{\circ}\right)$ El SNC del homo sapiens sapiens es una constante transcultural de la especie.

$\left.5^{\circ}\right)$ El SNC del homo sapiens sapiens es universal en la especie.

$\left.6^{\circ}\right)$ El SNC del homo sapiens sapiens es objetivo y finito (no es un sistema de deseos, reivindicaciones o demandas subjetivos infinitos).

$\left.7^{\circ}\right)$ Las necesidades y capacidades del SNC del homo sapiens sapiens no son susceptibles de intercambio.

$\left.8^{\circ}\right)$ Las necesidades y capacidades del SNC del homo sapiens sapiens se apoyan y

complementan.

\subsubsection{Estructura}

EI SNC se articula sobre nueve necesidades/capacidades estructurantes de la especie homo sapiens sapiens. A este número llegamos del siguiente modo:

a) Las investigaciones recientes en neurociencia, compartidas por la observación y reflexión de parte de la tradición filosófica, identifica lo que llaman tres funciones (ciencia) o facultades (filosofía), que estructuran la praxis. Para las cuales nosotros utilizaremos la categoría de necesidades/capacidades de energía. Estas son:

- Necesidad/capacidad cognitiva.

- Necesidad/capacidad afectiva.

- Necesidad/capacidad ejecutiva. 


\section{Tridimensionalidad estructural del SNC}



Fuente: elaboración propia.

\section{El árbol de la vida humana (de la naturaleza humana)}
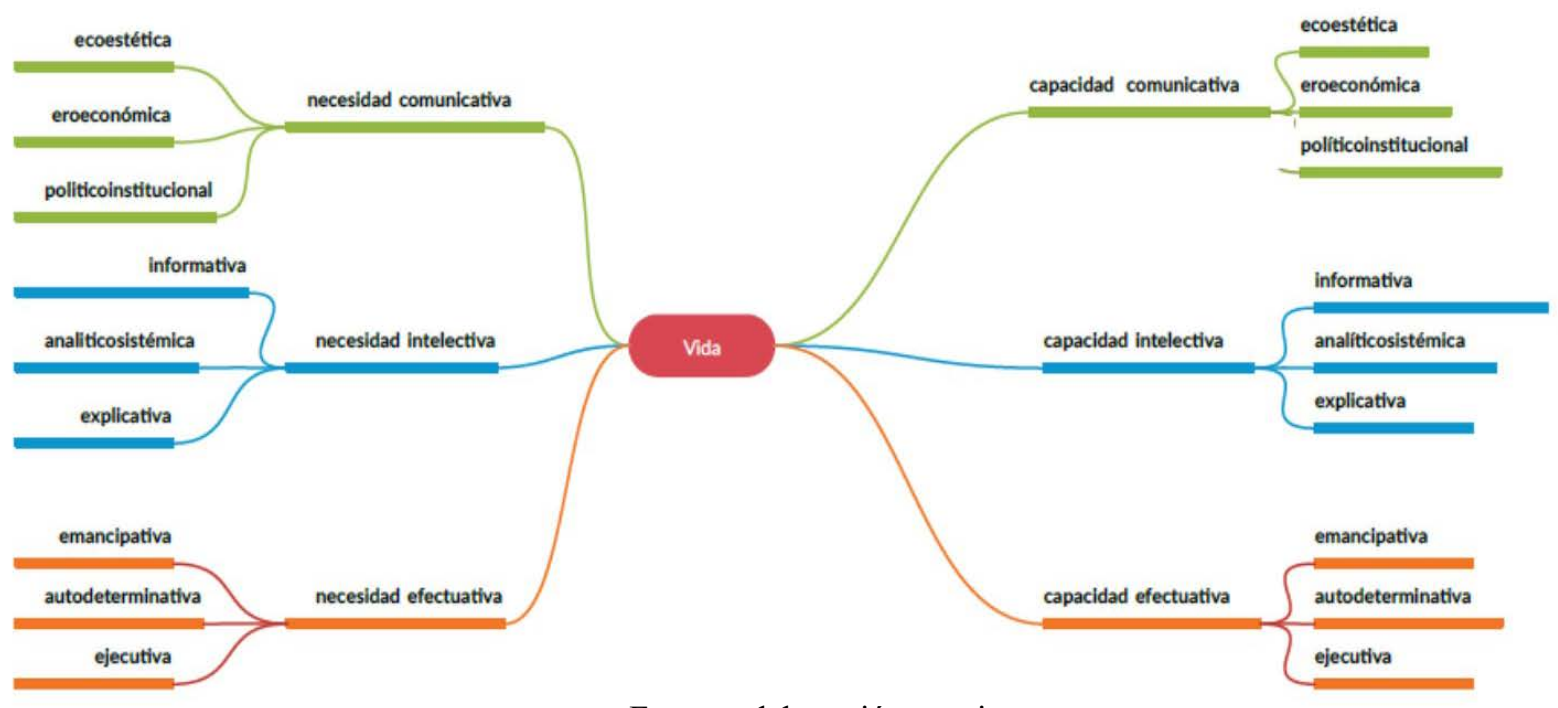

Fuente: elaboración propia.

b) La estructura tridimensional energética del dinamismo de la vida que organiza a su vez tridimensionalmente a cada una de las tres necesidades/capacidades en sus respectivos tres momentos (necesidades/capacidades) de toma de energía, combustión de la misma y donación de ella al medio (ver abajo).

En la propuesta de despliegue de la estructura del SNC que presentamos a continuación lo menos importante es el nombre con el que denominamos el elemento de la estructura, sino el contenido de la misma.

Resulta curioso que si giramos la imagen de la estructura del SNC encontramos algo parecido a la estructura del árbol de la vida, de la naturaleza del homo sapiens sapiens. Las necesidades vendrían a ser las raíces, el tronco, el cauce que permite el flujo de la energía (la savia), y las capacidades se asemejarían a las ramas, las hojas y el florecimiento del fruto. 


\section{Estructura del sistema de necesida- des / capacidades materiales de la especie homo sapiens sapiens ${ }^{1}$}

\section{$1^{\circ}$ Necesidades / capacidades afectivas (comunicativas).}

1. Necesidad/capacidad eco-estética.

2. Necesidad/capacidad ero-económica.

3. Necesidad/capacidad político-institucional.

\section{$2^{\circ}$ Necesidades / capacidades cognitivas.}

4. Necesidad/capacidad de aprehensión de realidad, de los hechos (información).

5. Necesidad/capacidad de análisis sistémico de los hechos.

6. Necesidad/capacidad de explicación de los hechos (conocimiento).

$3^{\circ}$ Necesidades/capacidades efectuativas (volitivas).

7. Necesidad/capacidad de liberación de energía.

8. Necesidad/capacidad autodeterminación.

9. Necesidad/capacidad ejecución histórica.

Teniendo en cuenta este sistema de necesidades/capacidades materiales (energéticas), aquí se postula que la vida de los pueblos es la dialéctica histórica, originaria y radical, de cada una de las necesidades/capacidades entre sí, y de cada una de ellas con la totalidad del sistema, en

1. I. Ellacuría hace un elenco de lo que llamamos capacidades, interpretándolas como fuerzas históricas: $\left(1^{\text {a }}\right)$ Fuerzas estrictamente naturales; $\left(2^{\mathrm{a}}\right)$ Fuerzas biológicas; $\left(3^{\mathrm{a}}\right)$ Fuerzas psíquicas; (4a) Fuerzas socio-económicas; $\left(5^{\mathrm{a}}\right)$ Fuerzas culturales e ideológicas; $\left(6^{\mathrm{a}}\right)$ Fuerzas políticas; $\left(7^{\mathrm{a}}\right)$ Fuerzas personales. ELLACURÍA, I., Filosofia de la realidad histórica, (Madrid: Trotta, 1991) 450-457. un dinamismo estructural de producción, circulación y apropiación de satisfactores históricos propios de cada cultura. Esta es la fuente de la diversidad cultural en la unidad estructural de la vida.

\subsubsection{Dinamismo histórico}

Si indagamos en el dinamismo energético de la materia viva, observamos que cuenta con una estructuración trimembre: 1) toma o captación de energía del medio por cada organismo según su modalidad; 2) afectación o combustión de la energía tomada del medio con y en la estructura propia de cada organismo; 3) emisión o donación de energía al medio según su modalidad.

Así, como hemos indicado, teniendo en cuenta los tres momentos del dinamismo en su articulación con las tres necesidades/capacidades que estructuran la vida del homo sapiens sapiens, el resultado son nueve necesidades/capacidades estructurantes. Estas nueve pueden desagregarse y concretarse, y de hecho lo hacen, en otras más, pero de un modo finito y objetivo. El postulado, que no pretende ser verdad dogmática, queda abierto a verificación o refutación científica y filosófica, así como a su progresivo desarrollo.

Lo que genera el movimiento histórico (también cultural) concreto del dinamismo de la vida es la urgencia de energía para la satisfacción y la fuerza energética de la capacidad de florecimiento:

$\left.1^{\circ}\right)$ Cada una de las necesidades y capacidades tiene un umbral bajo el cual su urgencia de satisfacción y realización respectiva se hace urgencia preferente sobre el resto de las necesidades y capacidades (ley de la urgencia respec- 


\section{Estructura del dinamismo energético de la materia viva}

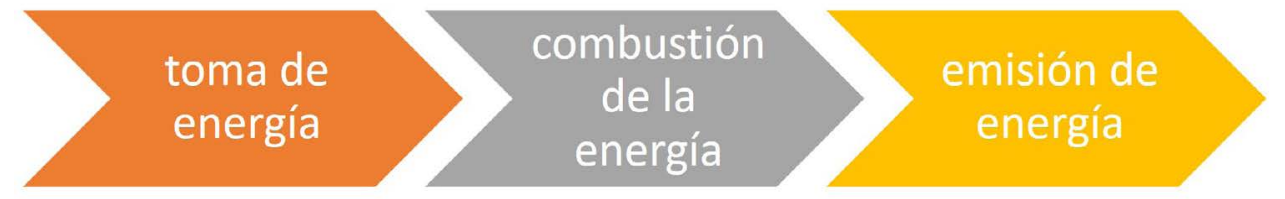

Dinamismo del sistema estructural de necesidades y capacidades de la vida
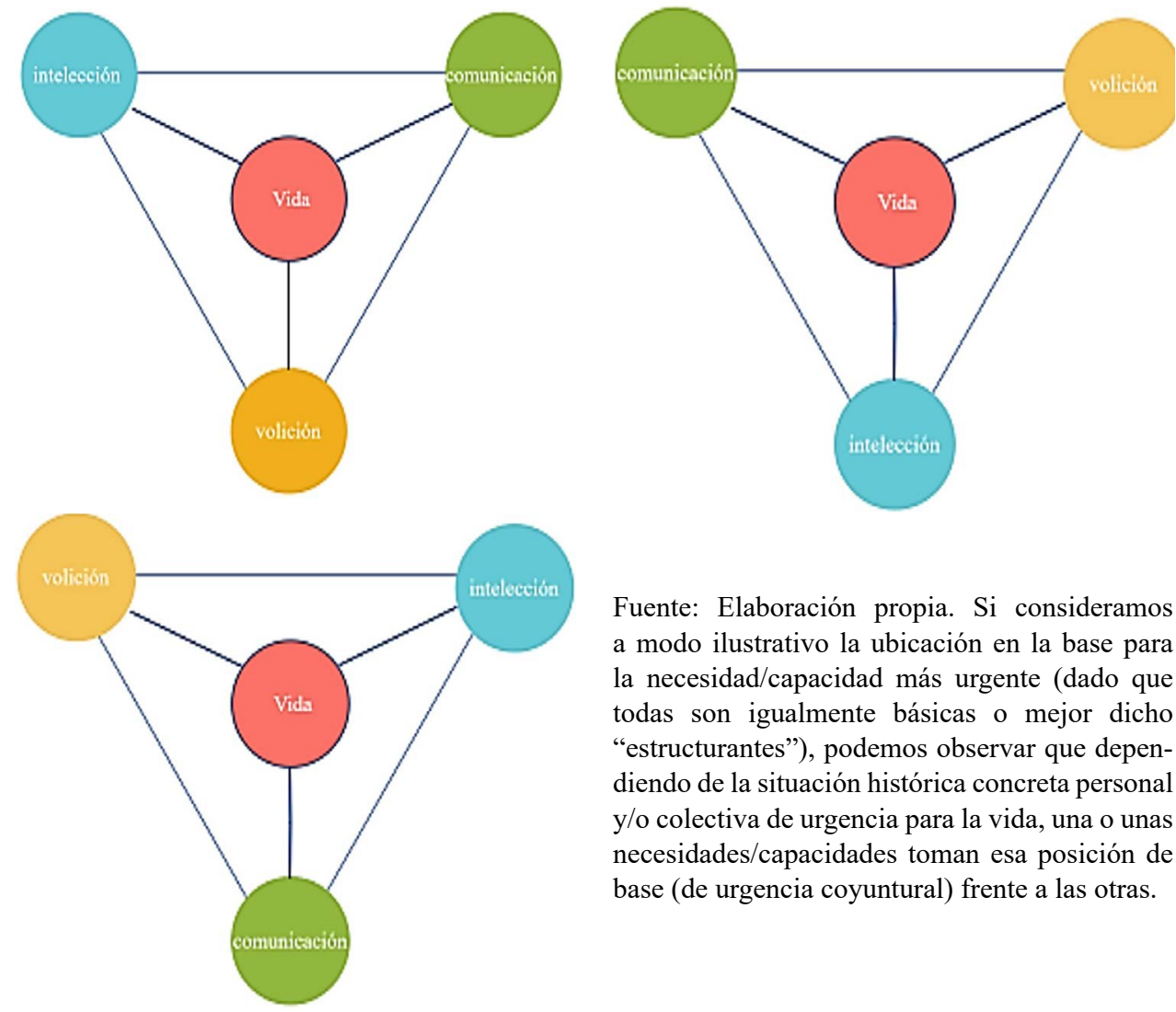

Fuente: Elaboración propia. Si consideramos a modo ilustrativo la ubicación en la base para la necesidad/capacidad más urgente (dado que todas son igualmente básicas o mejor dicho "estructurantes"), podemos observar que dependiendo de la situación histórica concreta personal y/o colectiva de urgencia para la vida, una o unas necesidades/capacidades toman esa posición de base (de urgencia coyuntural) frente a las otras.

tiva preferente de satisfacción y realización). Las NC forman un sistema integrado sin jerarquía fija, pero sí con preponderancias coyunturales dependiendo de la circunstancia histórica concreta.

$2^{\circ}$ ) La insatisfacción de las necesidades y el marchitamiento de las capacidades tiene un umbral que desencadena la fuerza para su satisfacción y floreci- miento. Si lo consigue se revierte dicha insatisfacción o marchitamiento, de lo contrario nos encontramos con un daño personal y/o colectivo, e incluso la muerte (ley de la reversión o el daño de la insatisfacción y marchitamiento).

$3^{\circ}$ ) El dinamismo energético de todas las necesidades/capacidades tiene una dimensión inconsciente, y puede tenerla consciente. 


\subsection{El sistema de valores y disvalores}

Llegados a este punto, ahora se entiende que los denominados valores morales tengan otro origen y contenido que principios abstractos que nadie sabe de dónde han salido o que debemos creer y asumir por tradición o creencia religiosa. Los llamados valores morales son la expresión o lectura ética o moral de la valencia que cada una de las acciones tiene respecto a la satisfacción/florecimiento o no del SNC. Este contenido material biológico de la ética o la moral es el fundamento de la misma, fundamento transcultural y constante de la especie. Un fundamento que es anterior a toda religión e instancia crítica de los códigos morales creados culturalmente. La praxis ética en la vida de los seres humanos es de capital importancia. Es la brújula de las acciones; el chip o programa de conducción de la vida. Si está bien orien- tada le llevará a la vida y su florecimiento intercultural, caso contrario a la muerte. Los esquemas que siguen pretenden mostrar dicha articulación entre el SNC con los valores, en su doble valencia de biovalores y disvalores, así como la tensión entre biovalores y disvalores.

\subsection{El sistema de derechos humanos de los pueblos y derechos de la Naturaleza}

La energía del SNC tiene, además de ética o moral, una expresión jurídica fundamental para la interculturalidad. Para entender esta afirmación y su alcance es necesario precisar lo que sea el Derecho. Por tal entendemos una praxis que tiene un poder real de satisfacer y florecer el sistema de necesidades/capacidades personal y colectivo, que la comunidad ha acotado como bienes merecedores de es-

\section{Estructura del sistema de necesidades / capacidades. Estructura del sistema de biovalores}

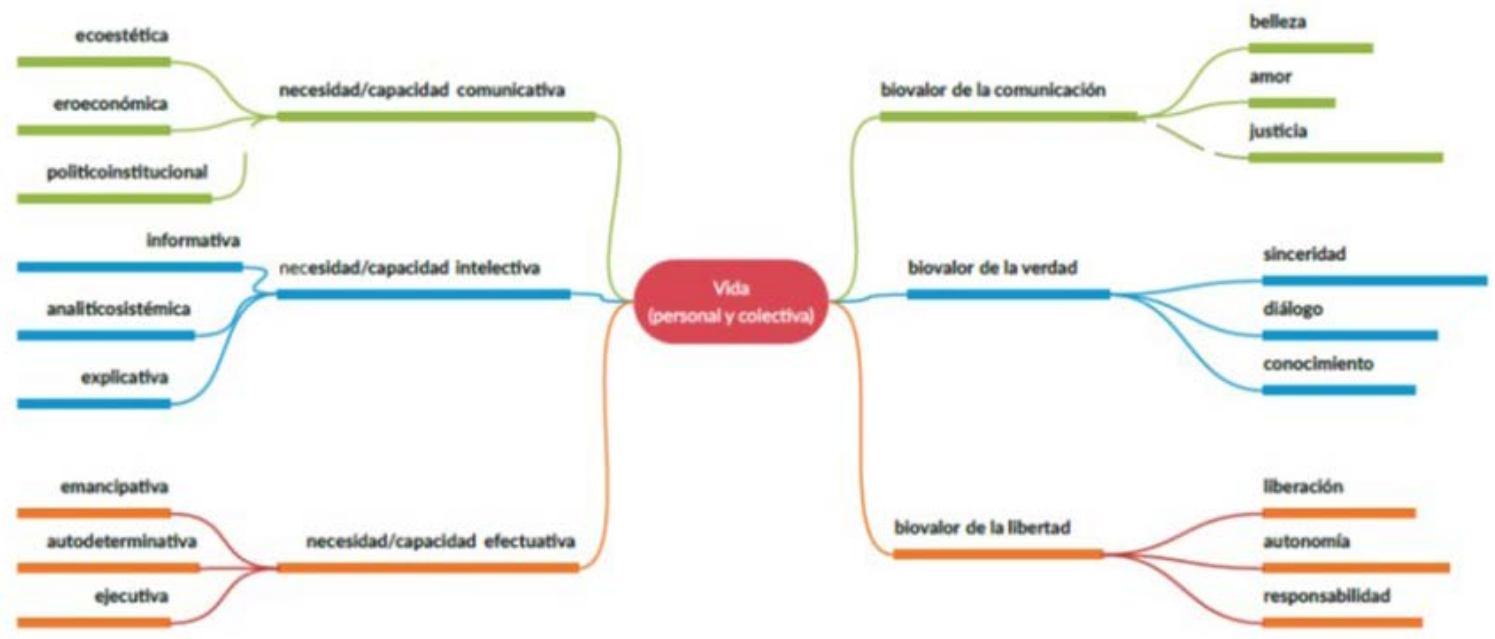

Fuente: elaboración propia. 


\section{Estructura del sistema de necesidades / capacidades. Estructura del sistema de disvalores}

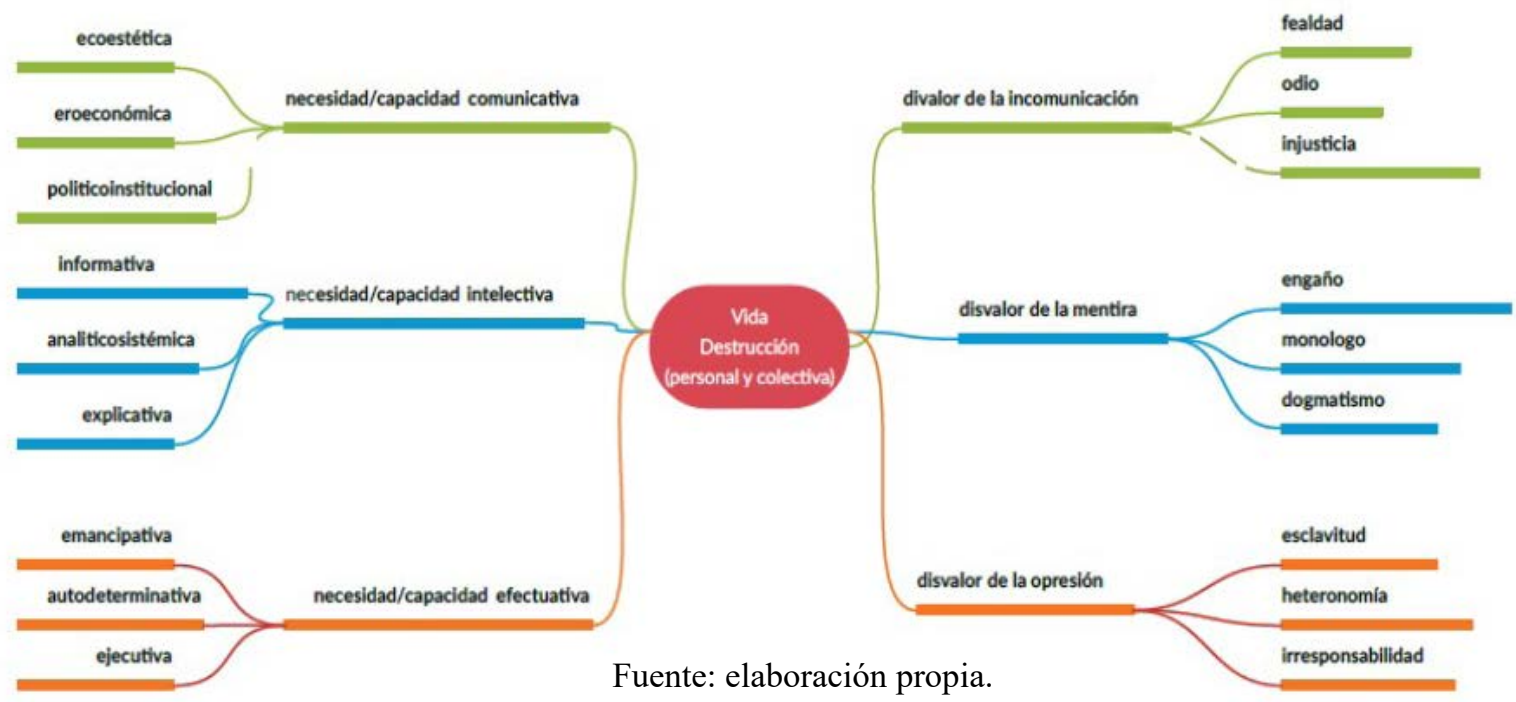

\section{Estructura del sistema de biovalores y disvalores}

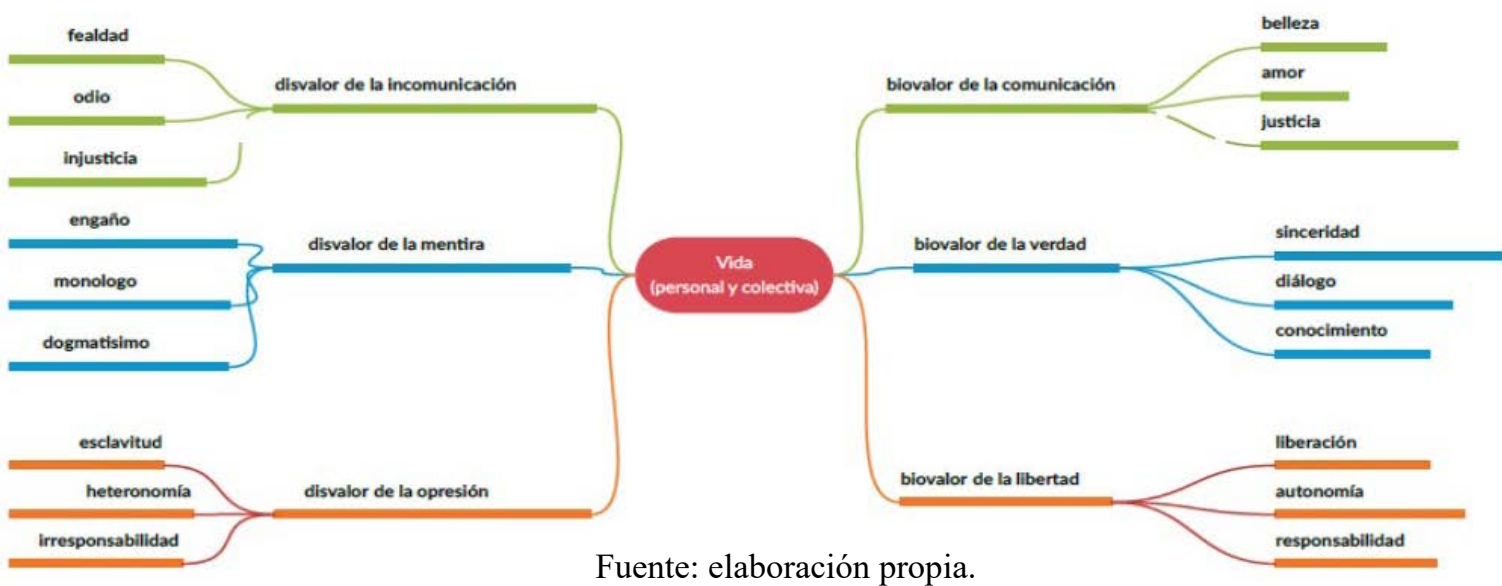

pecial protección para la producción y reproducción de la vida, y que cuenta con el apoyo de la fuerza tutelar coactiva comunitaria. El Derecho es por tanto una praxis autonormativa, legitimada, y físicamente coactiva, parte de la praxis moral-política. No se asume aquí, por considerarlo como falso, el postulado del escepticismo moral propio del idealismo y positivismo jurídico de la burguesía capitalista², así como

2. Un concepto de Derecho, común en la Sociología, lo define como: "el discurso prescriptivo autorizado, que or-ganiza y por ello legitima la violencia, y que es reconocido como tal, CORREAS, O., Pluralismo Jurídico. Alternatividad y Derecho Indigena (Ensayos) (México: Fontamara, 2003) 13. También es frecuente defi- 
tampoco el de cierto voluntarismo marxista supraestructural. Por el contrario, denunciamos la fenomenal expropiación que la burguesía ha llevado a cabo quitándole la moral al derecho de los pueblos y la Naturaleza. Dicha expropiación tenía y tiene una intención oculta más radical: a) la expropiación cultural a los pueblos de su fuente de legitimación originaria (la satisfacción y el florecimiento integrado del sistema de necesidades/ capacidades) capaz de deslegitimar el voluntarismo de quien manda; b) la imposición cultural etnocéntrica del positivismo jurídico, su ideología jurídica de clase. Así, para esa prédica el Derecho queda reducido a "... un cuerpo de procedimientos regularizados y patrones normativos, considerados justificables en un grupo social dado, que contribuyen a la creación, prevención y resolución de litigios, a través de un discurso argumentativo articulado bajo la amenaza de la fuerza" (Santos, 2003, 331).

Pues bien, en este horizonte o paradigma jurídico no capitalista, que hemos denominado iusmaterialista, el corazón, la médula del Derecho, es el Sistema de Derechos Humanos de los Pueblos y Derechos de la Naturaleza (SDHPDN). Este sistema se convierte en un satisfactor jurídico intercultural del SNC. En las necesidades y capacidades, en su satisfacción y florecimiento, tiene la fuente de su legitimidad, su contenido y brújula.

El que buena parte de los textos constitucionales aparezcan como algo medio anárquico y desarticulado en sus derechos se debe a los límites de las investi- gaciones del método científico aplicado a la organización política jurídica de la vida social; a los límites de los paradigmas jurídicos hegemónicos durante el constitucionalismo: el iusnaturalismo, el iusociocontractualismo y el iusvoluntarismo. Y al hecho de que casi la totalidad de las constituciones del planeta son expresión de la lucha de clases, y de la hegemonía del sistema capitalista. El resultado lo tenemos a la vista, una multitud de constituciones que lo mismo dan cabida a derechos que a contraderechos, carentes de criterio material organizativo de los derechos con la consecuente desarticulación interna, que fetichizan la letra escrita como Derecho, y que amputan buena parte de la vida jurídica de los pueblos.

La estructura constitucional de los derechos de los pueblos y la Naturaleza, y de la misma constitución de Naciones Unidas, no puede ser arbitraria. Ha de corresponderse con la estructura del sistema de necesidades/capacidades materiales de vida de los pueblos. Una propuesta de codificación de la 'Constitución de Naciones Unidas' articulando los Derechos Humanos en función del sistema de necesidades/capacidades, la hemos ofrecido, en colaboración con Alejandro Rosillo Martínez, en el Código de los Derechos Humanos de los Pueblos (Rosillo y Salamanca, ASLP, 2007). En función del sistema de necesidades/ capacidades, y de los $\mathrm{DHH}$, la estructura constitucional de los mismos sería la siguiente:

nir el Derecho como un conjunto de normas que regula la vida de un grupo organizado, cfr. Bobbio, N., Teoría General de la Política (Madrid, Trotta, 2009). 


\section{Estructura del Sistema de Derechos Humanos de los Pueblos y derechos de la Naturaleza}

\begin{tabular}{|ccc|}
$\begin{array}{c}\text { Derechos Humanos y de } \\
\text { Naturaleza de comunicación }\end{array}$ & $\begin{array}{c}\text { Derechos Humanos y de } \\
\text { Naturaleza de verdad }\end{array}$ & $\begin{array}{c}\text { Derechos Humanos y de } \\
\text { Naturaleza de libertad }\end{array}$ \\
\hline Derechos ecoestéticos & Derechos de Información & Derechos de Liberación \\
\hline Derechos eroeconómicos & Derechos de Opinión Crítica & Derechos Autodeterminación \\
\hline Derechos político-institucional & Derechos de Conocimiento & Derechos Ejecución histórica \\
\hline
\end{tabular}

Fuente: elaboración propia.

\section{La diversidad intercultural: el dinamismo histórico de los satisfactores y capacitadores}

En este texo no hemos abordado la riqueza de la diversidad de la praxis intercultural, pero lo común no se puede entender sin la diversidad. La diversidad cultural histórica de la Naturaleza de los pueblos es la riqueza fenotípica en que se manifiesta el genotipo 'cromosómico' de la estructura constitutiva de la especie homo sapiens sapiens. Utilizamos aquí el término 'genotipo' como metáfora, de modo más extenso que su contenido estricto de estructura genómica, incluimos también toda la constante fisiológica, neurofisiológica, y psicofisiológica de la vida humana. La vida y la muerte de los pueblos con la Naturaleza es el dinamismo histórico dialéctico entre la unidad estructural del sistema de necesidades/capacidades materiales de la especie humana con la diversidad de los distintos modos de producción, circulación y apropiación de sus satisfactores históricos (Rivaya, 2007, 240). El "genotipo", su estructura, no varía mientras no cambie la especie. Un cambio de esa estructura 'cromosómica' significaría un cambio de especie y/o aniquilación de la misma, como pretende el capitalismo transhumanista. Ese genotipo estructurante y propio de la especie es el que desde la prehistoria hasta hoy hace que los homo sapiens sapiens sigan siendo tales y no ángeles; que continúen buscando saciar su necesidad de hidratos de carbono, proteínas, cobijo, afecto, transporte, comunicación, autodeterminación, conocimiento, etc. En la prehistoria, con las uñas, a dentelladas, en cuevas, etc.; hoy, con cuchillo, tenedor y en restaurantes. Satisfactores y realizadores distintos para las mismas necesidades y capacidades.

La constante transhistórica y transcultural de las necesidades y capacidades requiere de la pluralidad y diversidad histórica y cultural de los satisfactores y realizadores: $\left.1^{\circ}\right)$ los satisfactores y realizadores forman sistemas históricos diversos, variables, históricos, culturalmente intercambiables, y cuya disponibilidad depende de la riqueza social y el proyecto político colectivo; $2^{\circ}$ ) los sistemas de satisfactores y de realizadores pueden ser sinérgicos o destructivos (ley de la respectividad bivalente de los satisfactores e insatisfactores, y de los realizadores y desrealizadores). Queda pendiente tratar el papel de la diversidad histórica de satisfactores y realizadores para la filosofía y práctica (praxis) intercultural de la liberación. 


\section{Conclusión}

Algunas de las propuestas de filosofía intercultural de la liberación, de ética de la liberación y de derecho de la liberación podrán contribuir al florecimiento de los pueblos si rompen las ataduras burguesas que conducen al monólogo multicultural o la esterilidad de la prédica idealista discursiva pseudointercultural. Entre algunas de ellas se encuentra su escepticismo cognitivo científico y epistemológico. Estos dogmas de la posmodernidad capitalista les ciegan caminos de práctica intercultural. Una posible vía de salida es la tradición del materialismo cultural marxista. Entendemos que en ella se puede ubicar al menos una brújula de saberes, contenido ético y legitimidad jurídica en la praxis intercultural desde abajo. También en ella el diálogo crítico con las culturas científicas es fundamental. En particular, puede resultar fecundo el estudio interdisciplinar e intercultural de la interacción del dinamismo dialéctico entre el sistema de necesidades/capacidades con la diversidad histórica en la producción, circulación y apropiación de sistemas de satisfactores y realizadores (capacitadores). Los sistemas de satisfactores y realizadores son ciertamente creaciones y expresiones culturales históricas diversas, plurales, ricas y potencialmente infinitas. Ahora bien, esa diversidad no se sustenta en el fatuo discurso sin saliva, ni es posible ni puede explicarse sin su articulación con un conjunto (sistema) de necesidades/capacidades constante y finito; que son a la vez psicobiológicas, antropológicas, sociológicas, etc. Constante histórica transcultural filética constitutiva del homo sapiens sapiens mientras no cambie la especie. Así, la vida y su repro- ducción es el fruto de la interacción de las tres dimensiones de la praxis material (cognitiva, afectiva y volitiva) con los tres momentos que estructuran el dinamismo energético de la misma (toma de energía del medio natural, combustión restructurante propia en comunicación con el medio externo e interno, y donación de energía al medio natural). De esa interacción surgen nueve necesidades/ capacidades germinales en el modo de realidad propio de nuestra especie: a) cognitivas ( $1^{\circ}$ aprehensivas, $2^{a}$ analiticosistémicas, y $3^{a}$ explicativas); b) afectivas o comunicativas ( $4^{\circ}$ ecoestéticas, $5^{\circ}$ eroeconómicas, $6^{\circ}$ politicoinstitucionales); c) volitivas o efectuativas ( $7^{\circ}$ liberadoras o emancipadoras, $8^{\circ}$ autodeterminativas, $9^{\circ}$ ejecutivas). En la crónica diaria de la lucha de los pueblos por la satisfacción vs. insatisfacción de su sistema de necesidades así como por el florecimiento vs. marchitamiento de su sistema de capacidades encuentra el fundamento las filosofías, las éticas y los derechos interculturales; y lo común su contenido.

\section{Bibliografía}

Bobbio, Norberto. (2009). Teoría General de la Ciencia Política, Madrid, Trotta.

Correas, Oscar. (2003). Pluralismo jurídico, alternatividad y derecho indígena Ensayos, México, Fontamara.

De Sousa Santos, Boaventura. (2003). Crítica de la razón indolente: contra el desperdicio de la experiencia: para un nuevo sentido común: la ciencia, el derecho y la política en la transición paradigmática, Bilbao, Desclée de Brouwer.

Ellacuría, Ignacio. (1991). Filosofía de la realidad histórica, Madrid, Trotta. 
Fornet-Betancourt, Raúl. (2001). Transformación del marxismo en América Latina, México, UANL.

Fornet-Betancourt, Raúl. 2001. Transformación intercultural de la filosofía: ejercicios teóricos y prácticos de filosofía intercultural, desde Latinoamérica en el contexto de la globalización, Bilbao, Desclée de Brouwer.

Harris, Marvin. (1994). El materialismo cultural, Madrid, Alianza.

Monod, Jacques. (1971). El azar y la necesidad: ensayo sobre la filosofía natural de la biología moderna, Caracas, Monteavila editores.

Proto Fernando e Issa Agustina (Coords.). (2021). Introducción a la Filosofía Intercultural de la Liberación, Buenos Aires, Arkho Ediciones.

Rivaya García, Benjamín. (2007). El materialismo jurídico: la presunta teoría del derecho de Marvin Harris, Madrid, Dykinson.

Rosillo Martínez, A.; Salamanca Serrano, A., (2007). Código de los derechos humanos de los pueblos, 2 vols, México, UASLP.

Salamanca Serrano, Antonio (2021), Las fuerzas esenciales del florecimiento vs Guerra contra la naturaleza humana. Capitalismo transhumanista vs revolución de los humanish. En prensa.

Salamanca Serrano, Antonio. (2003). Fundamento de los derechos humanos, Madrid, Nueva Utopía.

Salas Astrain, Ricardo. (2006). Ética intercultural: ensayos de una ética discursiva par*a contextos culturales conflictivos.(Re)lecturas del pensamiento latinoamericano, Quito, Abya-Yala.
Sánchez Rubio, D. (2021). Humanismo intercultural biocentrado: una propuesta desde lo común. Anuario de Filosofía del Derecho, aparición en 2022.

Zubiri, Xavier. (1995). Estructura dinámica de la realidad, Madrid, Alianza Editorial. 

